\title{
The Third Trochanter of Femur - An Anatomical Study
}

IJCRR

Section: Healthcare

Sci. Journal Impact

Factor: 6.1 (2018)

ICV: 90.90 (2018)

(c) (i) (9)

Copyright@IJCRR

\section{Gyanaranjan Nayak ${ }^{1}$, Saurjya Ranjan Das ${ }^{1}$, Sitansu Kumar Panda², B Shanta Kumari ${ }^{3}$}

\begin{abstract}
'Associate Professor, Department of Anatomy, IMS and SUM Hospital, Siksha 'O' Anusandhan Deemed to be University, Bhubaneswar, Odisha 751003, India; 'Professor, Department of Anatomy, IMS and SUM Hospital, Siksha 'O' Anusandhan Deemed to be University, Bhubaneswar, Odisha 751003, India; 'Assistant Professor, Department of Anatomy, IMS and SUM Hospital, Siksha 'O' Anusandhan Deemed to be University, Bhubaneswar, Odisha $75^{1003}$, India.
\end{abstract}

\section{ABSTRACT}

Background: The third trochanter is a rounded, linear or conical projection along the superior border of gluteal tuberosity of the femur. Purpose of the study is to find the frequency of the third trochanter in human femora and determine its dimensions and its distance from the tip of greater trochanter of the femur.

Methods: Sixty dry human femora (thirty right and thirty left) were examined for the presence of third trochanter, their dimensions and their distance from greater trochanter being measured by slide calliper.

Results: The third trochanter was noted in $21.66 \%$ cases. Their mean length and width were found to be $2.61 \pm 0.97 \mathrm{~cm}$ and $0.96 \pm 0.15 \mathrm{~cm}$ respectively. The average distance of the third trochanter from the tip of the greater trochanter was found to be $6.81 \pm 0.64 \mathrm{~cm}$.

Conclusion: The current study will be useful in anthropometry and orthopaedics.

Key Words: Anthropometry, Gluteal tuberosity, Third trochanter

\section{INTRODUCTION}

The femur is the longest and strongest bone in the human body. It is a principal weight-bearing bone. The femoral architecture may get altered due to functional demand during any day to day activities. One such variation is the third trochanter of the femur. The third trochanter of femur is a rounded, oblong or conical elevation present on the upper end of gluteal tuberosity. ${ }^{1}$ The gluteal tuberosity of femur provides insertion of one-fourth fibres of the muscle, gluteus maximus. Gluteus maximus function may exert a mechanical loading on the gluteal tuberosity and change its morphology. The presence of bony crests, ridges and tuberosities may directly correlate with a constant augmented muscle pull.

In anthropometric observations, the third trochanter is commonly used as a non-metric variation in the post-cranial skeleton. ${ }^{2}$ The third trochanter appears prominently in anthropometric, comparative and functional studies. The relation between muscle insertion and topography of fracture lines in pertrochanteric fractures of proximal part of femur has been established in details. Bone with only periosteal covering and lacking muscular and ligamentous attachment provides negligible resistance against onset of fractures. So variable patterns in dimensions of fragments of pertrochanteric fracture of femur depends on variable locations and sizes of soft tissue attachment on that part of femur. ${ }^{3}$ Apart from its role in causing variable patterns of pertrochanteric fractures of femur, the third trochanter may provide increased skeletal mass as a reinforcement for the proximal femoral diaphysis in response to increased ground reaction force. ${ }^{3}$ The third trochanter as already stated provides attachment to the ascending tendon of gluteus maximus. Femoral attachment of gluteus maximus hints towards a strong mechanical effort of the hip joint in extension, stabilisation and control of the thigh thereby providing medio-lateral reinforcement to resist high mechanical stress in erect posture and locomotion. ${ }^{3}$ Therefore the third trochanter may serve to augment the attachment surface area for gluteal musculature and cause greater efficiency of contraction. In some species of laboratory mammals, the third trochanter of the femur has been

\section{Corresponding Author:}

Dr. Gyanaranjan Nayak, Associate Professor, Department of Anatomy, IMS and SUM Hospital, Siksha 'O' Anusandhan Deemed to be University, Bhubaneswar, Odisha 751003; Mobile: 09937750477; Email: drgrn82@gmail.com

ISSN: 2231-2196 (Print)

Received: 15.07 .2020
ISSN: $0975-5241$ (Online)

Revised: 22.09 .2020
Accepted: 18.10 .2020
Published: 07.12 .2020 
established as a necessary anatomical landmark for biomechanical study and an access point for the medullary cavity. ${ }^{4}$

As there is the paucity of literature regarding the third trochanter of femur we have endeavoured to throw light upon the frequency, dimensions and location of the supposedly significant anatomical entity.

\section{MATERIALS AND METHODS}

The study included sixty adult dry human femur bones (thirty left and thirty right) of either sex used in teaching routine osteology to undergraduate MBBS students. Bones which were broken, deformed or with evident pathological features were excluded from the study. All the femur bones were observed macroscopically for the presence of the third trochanter and the frequency was noted. The maximum length and width of the respective third trochanters were measured using slide calliper. The distance of each third trochanter from the tip of the greater trochanter was also measured using slide calliper.

\section{Statistical analysis}

All the data were tabulated and analysed using Microsoft Excel software. Mean and standard deviation for the morphometric parameters was obtained. The unpaired t-test was applied and p-value less than 0.05 was considered significant.

\section{RESULTS}

A distinct third trochanter (Figure 1, Figure 2) was observed in thirteen out of sixty bones (21.66\%). Left-sided femur bones showing the third trochanter were nine in number $(30 \%)$ whereas right-sided femur bones showing the third trochanter were four in number (13.3\%). So a left-sided predominance was observed in our study. The dimensions and distance of the third trochanter from the greater trochanter are tabulated in Table 1. The average maximum length of the third trochanter was found to be $2.66 \pm 1.1 \mathrm{~cm}$ on the left side, $2.5 \pm 0.69 \mathrm{~cm}$ on the right side and $2.61 \pm 0.97 \mathrm{~cm}$ on both sides. The value was more on the left side but the difference was not statistically significant. The average maximum width was obtained as $0.95 \pm 0.16 \mathrm{~cm}$ on the left side, $0.97 \pm 0.15 \mathrm{~cm}$ on the right side and $0.96 \pm 0.15 \mathrm{~cm}$ on both sides. The average maximum width was more on the right side and the difference was not statistically significant. The average distance of the third trochanter from the tip of the greater trochanter was noted to be $6.84 \pm 0.63 \mathrm{~cm}$ on the left side, $6.75 \pm 0.77 \mathrm{~cm}$ on the right side and $6.81 \pm 0.64 \mathrm{~cm}$ on both sides. The average distance of the third trochanter from greater trochanter was more on the left side, the difference being statistically insignificant (Figure 1 and 2).

\section{DISCUSSION}

The third trochanter is noted as an osseous tubercle on the upper portion of gluteal tuberosity of the femur. It is usually located lateral to the line joining the tip of greater trochanter with the superior bifurcation of linea aspera of femur. It is used as a common non-metric variation of the post-cranial skeleton in anthropometric studies of various populations. The third trochanter is mainly defined as the site of insertion of the muscle gluteus maximus. Its presence in human beings is probably the result of the strengthening of this muscle in humanoids in contrast to other primates. Another role of the third trochanter may be to alter the direction of the insertion of the tendon of gluteus maximus muscle. The third trochanter being a pulley like a prominence at the upper part of gluteal tuberosity alters the direction of the tendon of the said muscle before it inserts to the rest of the tuberosity. ${ }^{5}$

A frequency of $6.6 \%$ for the third trochanter with left-sided prominence is reported. ${ }^{6}$ Finnegan ${ }^{2}$ has reported right-side predominance in the White and left side predominance in the Negro. It is also described the frequency of the third trochanter as $20 \%$ in an Indian study. ${ }^{7}$ Muthukumaravel and Manjunath $^{8}$ have reported a frequency of $13.72 \%$ in their study with a right-sided predominance $(15.71 \%$ on the right side and $12.04 \%$ on the left side). They have reported vertical length of the third trochanter as $20.1 \mathrm{~mm}$ on the right side and $8.18 \mathrm{~mm}$ on the left side. Chaparral et al have reported a frequency of $14 \% .{ }^{9}$ In their study, the average length of the third trochanter was $7.69 \mathrm{~mm}$ on the right side and $15.48 \mathrm{~mm}$ on the left side whereas the average width was $4.9 \mathrm{~mm}$ on the right side and $7.52 \mathrm{~mm}$ on the left side.

The occurrence of bony crests, ridges and tuberosities are related to the function of contiguous muscle activity. Genetic factors were originally indicated to regulate phenotypic development and expression of discontinuous skeletal traits including features like the third trochanter of femur ${ }^{10}$. However recent findings have elaborated the role of various biological and environmental factors such as age, sex, nutrition and side dependence influencing manifestations of certain nonmetric traits in human population and lower animals ${ }^{11,12}$.

\section{CONCLUSION}

The knowledge of the occurrence of the third trochanter of femur is crucial in diagnosing and managing pertrochanteric fracture and in the study of microevolutionary trends in anthropometric and comparative studies of humans.

\section{ACKNOWLEDGEMENT}

Authors acknowledge the immense help received from the scholars whose articles are cited and included in references 
to this manuscript. The authors are also grateful to authors/ editors/publishers of all those articles, journals and books from where the literature for this article has been reviewed and discussed.

\section{Conflicts of interest: None.}

Ethical clearance not required.

\section{REFERENCES}

1. Lozanoff S, Sciulii PW, Schneider KN. Third trochanter incidence and metric trait covariation in the human femur. J Anat 1985; 143:149-59.

2. Finnegan M. Non-metric variation of the intracranial skeleton. J Anat 1976;125:23-37.

3. Ghosh S, Sethi M, Vasudeva N. Incidence of the third trochanter and hypotrochanteric fossa in human femora in Indian population. OA Case Reports 2014;3(2):14.

4. Sylvia S, Ahmed MK, Jainapur P. Third trochanter of human femora in north Karnataka region. Int J Anat Res 2015;3(2):1011-14.

Table 1: Table showing parameters of the third trochanter of the femur

\begin{tabular}{lcccc}
$\begin{array}{l}\text { Parameter of } \\
\text { third trochanter }\end{array}$ & $\begin{array}{c}\text { Left side } \\
(\mathbf{n}=\mathbf{9})\end{array}$ & $\begin{array}{c}\text { Right side } \\
(\mathbf{n}=\mathbf{4})\end{array}$ & $\begin{array}{c}\text { Total } \\
(\mathbf{n}=\mathbf{1 3})\end{array}$ & $\begin{array}{c}\mathbf{p} \\
\text { value }\end{array}$ \\
$\begin{array}{l}\text { Maximum length } \\
\text { (in cm) }\end{array}$ & $2.66 \pm 1.1$ & $2.5 \pm 0.69$ & $2.61 \pm 0.97$ & 0.74 \\
$\begin{array}{l}\text { Maximum width } \\
\text { (in cm) }\end{array}$ & $0.95 \pm 0.16$ & $0.97 \pm 0.15$ & $0.96 \pm 0.15$ & 0.84 \\
$\begin{array}{l}\text { Distance from } \\
\text { tip of greater tro- } \\
\text { chanter (in cm) }\end{array}$ & $6.84 \pm 0.63$ & $6.75 \pm 0.77$ & $6.81 \pm 0.64$ & 0.83 \\
\hline
\end{tabular}

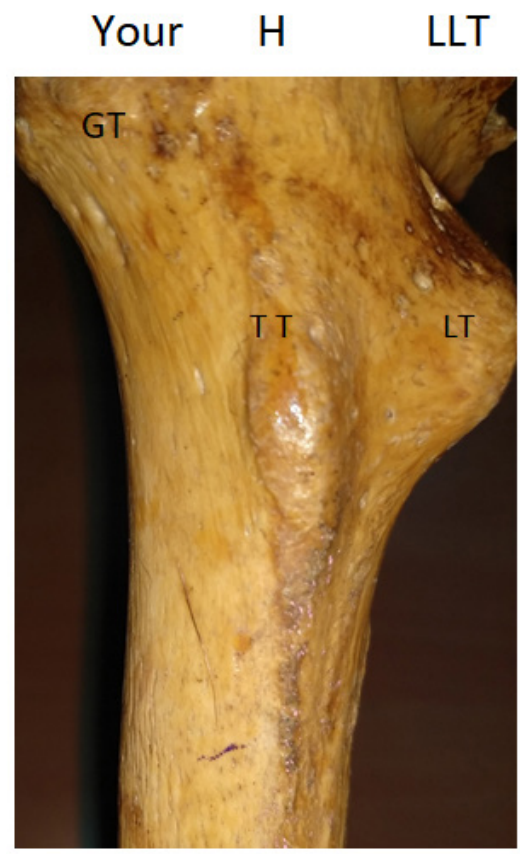

Figure 1: Upper end of femur showing third trochanter, GTGreater trochanter, LT- Lesser trochanter, TT- Third trochanter.
5. Ajita R, Jaishree A, Sangma GT, Purnabati S. The third trochanter in the human femur: a case report. JEMDS 2015;4(41):72248.

6. Bolanowski W, Smiszkiewicz- Skwarska A, Polgui M, Jedrzejewski K. The occurrence of the third trochanter and its correlation to certain anthropometric parameters of the human femur. Folia Morphol 2005;64(3):168-75.

7. Faruqi NA. The Femur- Chapter $12^{\text {th }}$ in Human Osteology, $2^{\text {nd }}$ Ed, New Delhi, CBS Publishers. 2006:114.

8. Muthukumaravel N, Manjunath KY. A study on the occurrence of the third trochanter in the femora in northern Tamil Nadu region. NJCA 2015;4(4):186-9.

9. Chhaparwal R, Bhadkaria V, Chhaparwal N. Incidence of third trochanter $\backslash$ crista glutei in human femora in central Indian population. JKIMSU 2017:6(2):57-62.

10. Carolinberry A, Berry RJ. Epigenetic variation in the human cranium. J Anat 1967; 101:361-79.

11. Howe WL, Parsons PA. Genotype and environment in the determination of minor skeletal variants and body weight in mice. J Embroyl Exp Morphol 1967; 17:283-92.

12. Dahinten SL, Pucciareli HM. Effect of age, sex and nutrition on discontinuous traits of rat skull. Acta Anat (Basel). 1981;110(2):159-63.

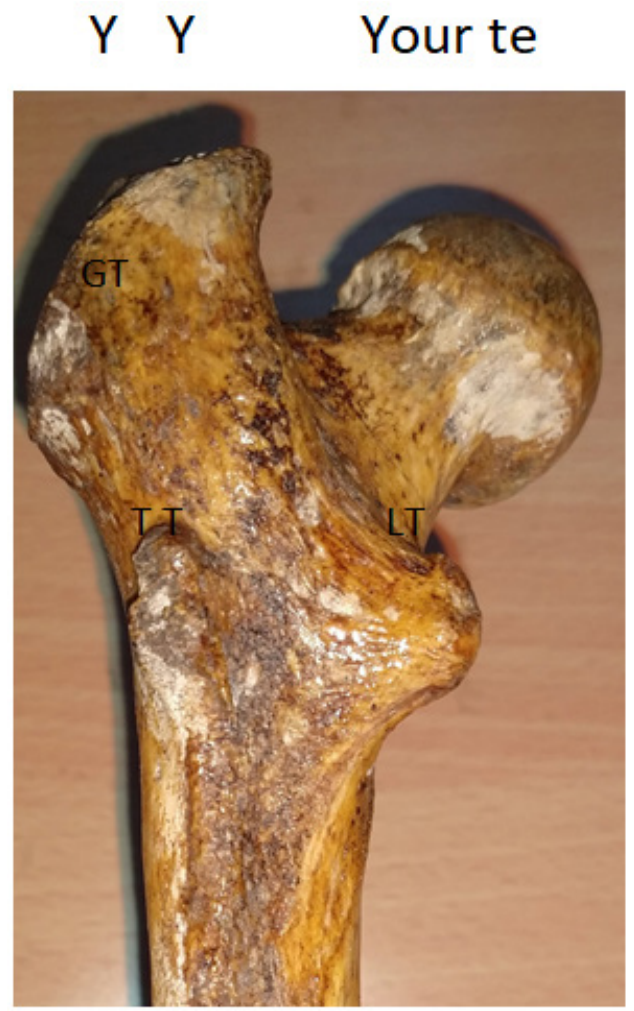

Figure 2: Upper end of femur showing third trochanter, GTGreater trochanter, TT- Third trochanter. 